\title{
THE FIRST RECENT SPECIES OF PROTOMUTILLA (HYMENOPTERA: MUTILLIDAE; MYRMOSINAE) ${ }^{1}$
}

\author{
By Denis J. Brothers ${ }^{2}$
}

During a recently completed study of the higher classification of the aculeate Hymenoptera (Brothers, 1974), my attention was drawn to a female specimen from India representing a species of Myrmosinae (considered a subfamily of Tiphiidae by many authors, e.g., Krombein, 1940) but showing marked similarities to Nanomutilla (a member of the Mutillidae often included in the Myrmillinae). This situation is reminiscent of that found by Bischoff (1915) for seven female specimens in Baltic amber. All of these have the welldeveloped pro-mesonotal suture characteristic of the Myrmosinae, but in addition "die Tiere weisen Beziehungen zu verschiedensten Gattungen auf, so zu Myrmilla, Nanomutilla, Mutilla s. str. etc." Bischoff described the genus Protomutilla to include these seven species, and considered it best placed in the "Mutillinae", although intermediate between this taxon and the "Myrmosinae" (which he considered to be a member of the Mutillidae). He listed the most characteristic features of the genus as: the distinctly developed promesonotal suture, the transverse first abdominal (metasomal) segment, the lack of a pygidial area, the usually longitudinally striate sculpturing of the mesonotal region, and the absence of long pubescence. In addition, all of his specimens have the posterolateral angles of the mesosoma acute or dentate. The Indian specimen possesses all these characters except for that of the mesonotal sculpturing (absent in some of Bischoff's species also). The form of the posterolateral angles of the propodeum differentiates this genus from the others with a well-developed pro-mesonotal suture, so that the Indian specimen seems best considered to represent a modern species of Protomutilla. Placement of this genus in the Myrmosinae is supported by the almost straight and well-differentiated hind margin of the pronotum and also by the presence of a well-developed carina dorsally on the hind coxa (a character not mentioned by Bischoff), although this is not as markedly lamellate as in most other myrmosines.

\footnotetext{
${ }^{1}$ Contribution number 1538 from the Department of Entomology, University of Kansas, Lawrence, Kansas 66045.

${ }^{2}$ Present address: Department of Entomology, University of Natal, Pietermaritzburg, South Africa.

Manuscript received by the editor January 21, 1974.
} 


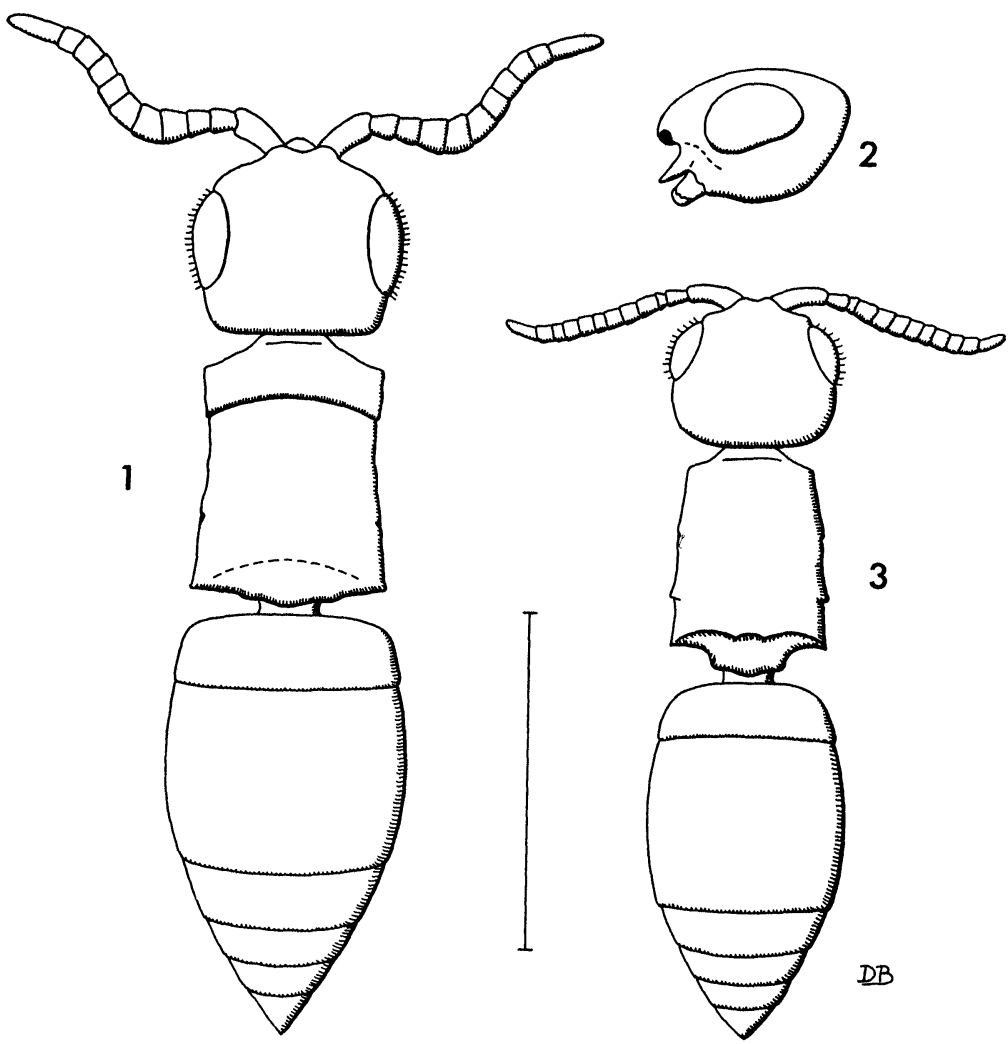

Figs. 1-2. Protomutilla microsoma, sp. nov., + . 1, dorsal view, legs omitted; 2, head, lateral view, antenna and palpi omitted. Fig. 3. Nanomutilla microsoma André, + , dorsal view, legs omitted. Scale $=1.0 \mathrm{~mm}$. 


\title{
Protomutilla microsoma sp. nov.
}

\author{
(Figs. I-2)
}

FEMALE: Length $2.6 \mathrm{~mm}$. Body finely and evenly punctate with sparse, short, pale pubescence; black except clypeus, antennal tubercle, antenna, mandible, ventral third of pronotum laterally, legs, fifth and sixth metasomal segments and apical margins of other metasomal segments testaceous, and palpi stramineous. Head almost prognathous, I.I times as wide and 0.7 times as high as long, I.I times as wide as mesomoma; sides weakly converging behind eye, about 0.3 times length of eye; ocelli absent; eye broadly oval, with many short setae; frons evenly swollen, produced between barely differentiated antennal tubercles; malar space 0.4 times as long as eye; weak genal carina present; clypeus flattened, anteriorly produced with strongly convex apical margin; antenna with scape 3.0 times as long as wide, pedicel about as long as first flagellar segment which equals second in length, flagellum widest at third segment; mandible approximately parallelsided, obliquely tridentate, the apical tooth strongest. Mesosoma I.4 times as long (excluding anterior collar) as wide; width at humeral angle 0.9 times that at propodeal angle. Pronotum (excluding collar) 0.3 times as long as wide; hind margin shallowly concave; lateral margins slightly convergent posteriorly; humeral angle pronounced. Mesonotum approximately parallel sided, o.9 times as wide as pronotum. Propodeum with lateral margins divergent posteriorly, forming a strong dentiform angle on each side; disc and declivity barely differentiated. Mesosomal pleura differentiated from nota by a longitudinal carina; concave except convex posteriorly forming propodeal angle. Legs unmodified; foretarsus without spines (i.e., pecten undeveloped); hind coxa with obtuse lamellate tooth dorsally; hind tibia without spines externally, only a very few minute spines apically. Metasoma about I.7 times as long as wide, I.25 times as wide as mesosoma; first tergum 0.4 times as long as wide, about as wide as and 0.4 times as long as second; sixth tergum sparsely punctate, without differentiated pygidial area; first sternum with single blunt anteriorly-directed midventral tooth.

MALE: Unknown.

holotype: $q$, [India, Orissa Prov.], Nilgiri Hills, $3500 \mathrm{ft}$. (H. L. Andrewes); in Hope Department, University Museum, Oxford, England. (No date of collection given.) The specimen is unfortunately damaged, and lacks the apical three segments of the left foretarsus, the left mid- and hind and right mid-tibiae and tarsi; the left antenna is glued to the card bearing the "minutan" 
pin. Since the specimen has been remounted from a glued card mount, some features of the venter and appendages remain somewhat obscured by glue.

Although Bischoff's (1915) descriptions are very short, P. microsoma seems clearly to differ from all the amber species. It may be most similar to $P$. nana, but the head undoubtedly differs in form from that species.

The resemblance of $P$. microsoma to Nanomutilla (Fig. 3 ) is quite remarkable, the most basic difference being the form of the pro-mesonotal suture. In addition to gross body form, these species have highly similar coloration and puncturation, and all are rather small in size. Nanomutilla even has a weakly developed carina on the hind coxa as well as pubescent eyes, characters lacking in the higher Mutillidae. These marked similarities tend to support my conclusions (elaborated in Brothers, I974) that the Myrmosinae should be considered a subfamily of Mutillidae.

\section{AcKNowledgements}

I should like to thank Mr. Christopher O'Toole of Oxford for bringing this specimen to my attention, and also Mr. W. L. Overal of the Univesity of Kansas for his help with preparation of the manuscript.

\section{REFERENCES}

BischoFF, $\mathrm{H}$.

1915. Bernsteinhymenopteren. Schrift. Phys.-Oekon. Ges., Königsberg 56: $139-144$.

BRothers, D. J.

1974. Phylogeny and classification of the aculeate Hymenoptera, with special reference to Mutillidae. Univ. Kansas Sci. Bull. (submitted).

Krombein, K. V.

1940. Studies in the Tiphiidae (Hymenoptera Aculeata). IV. A revision of the Myrmosinae of the New World with a discussion of the Old World species. Trans. American Ent. Soc. 65: 415465 , pl. 24. 

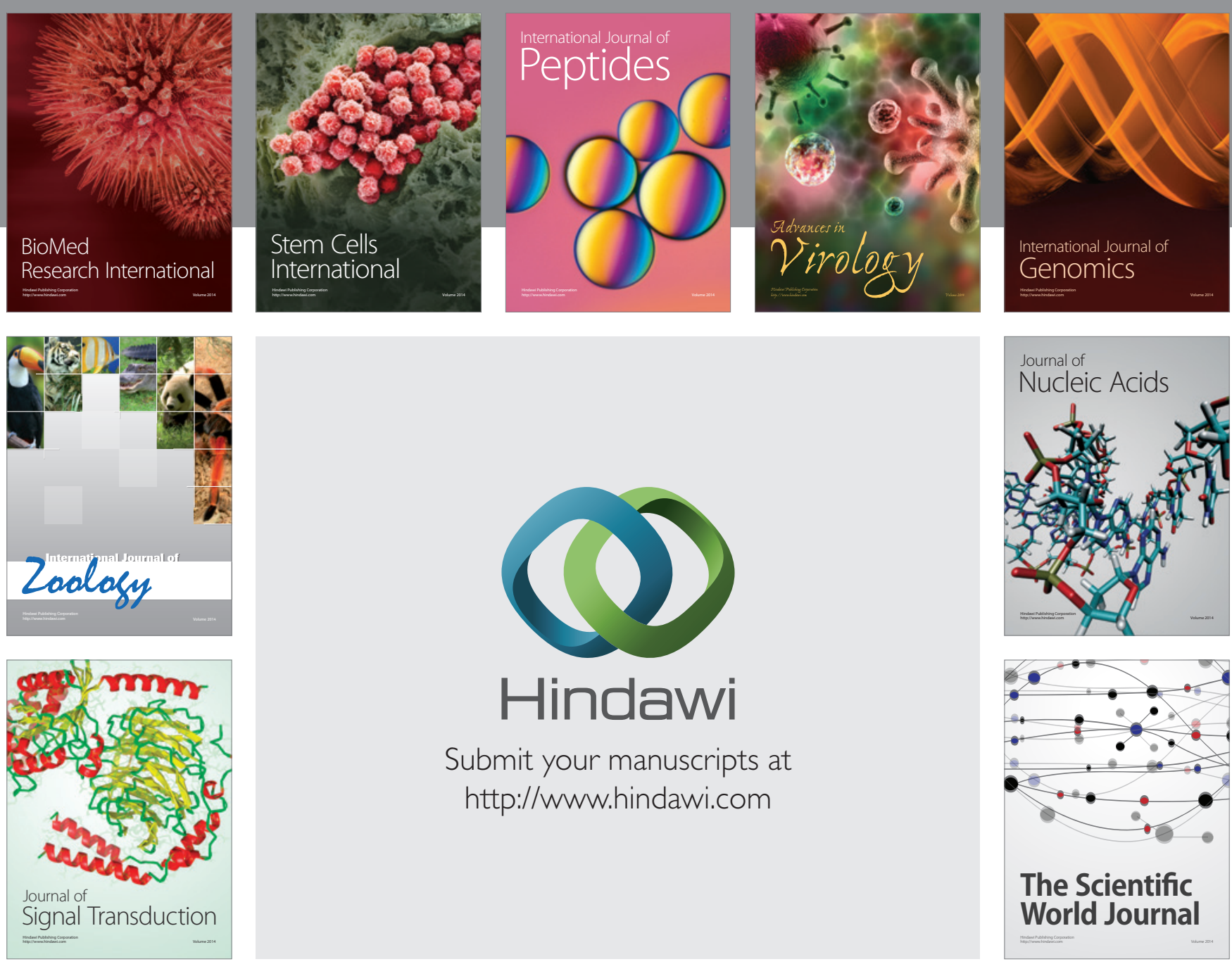

Submit your manuscripts at

http://www.hindawi.com
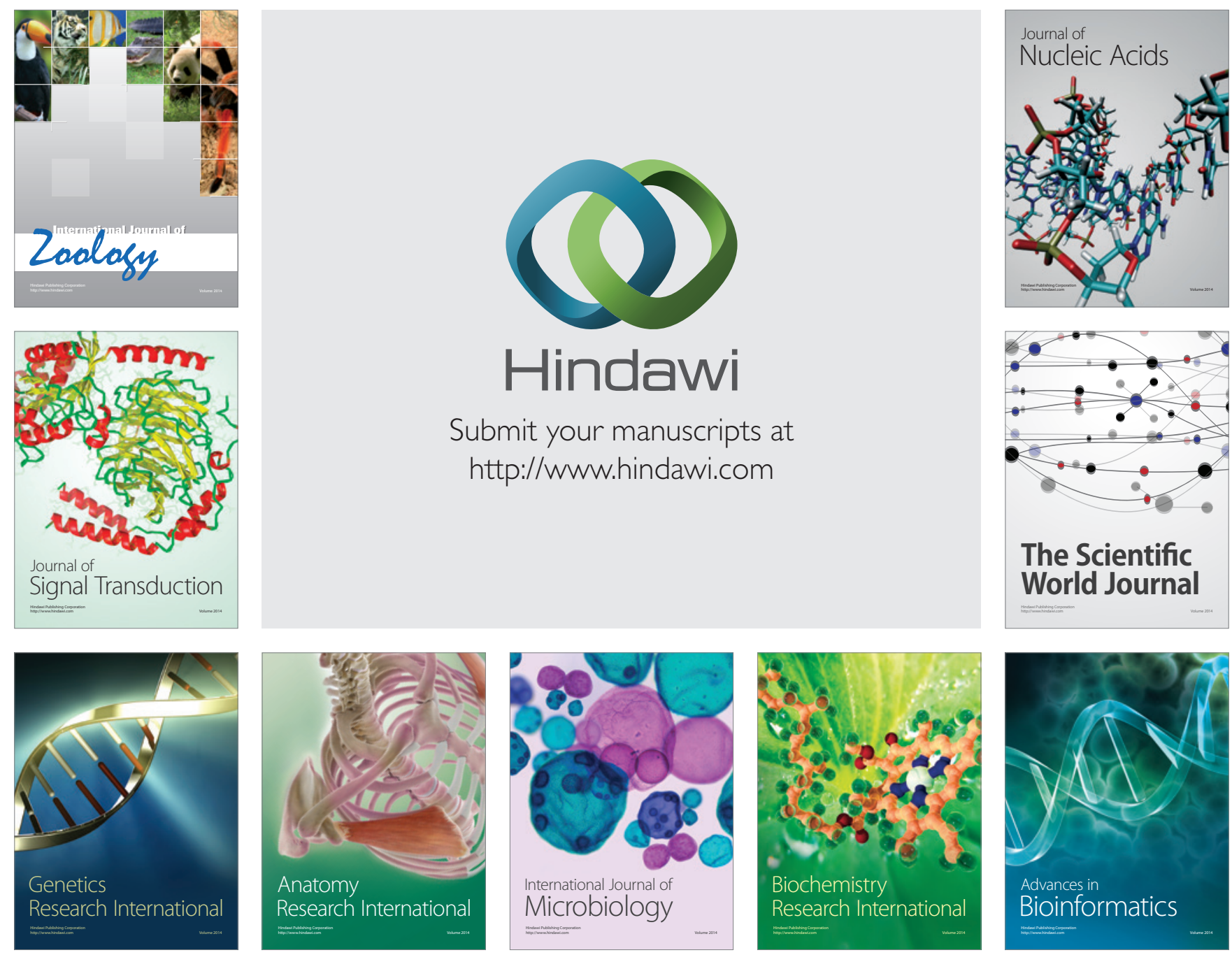

The Scientific World Journal
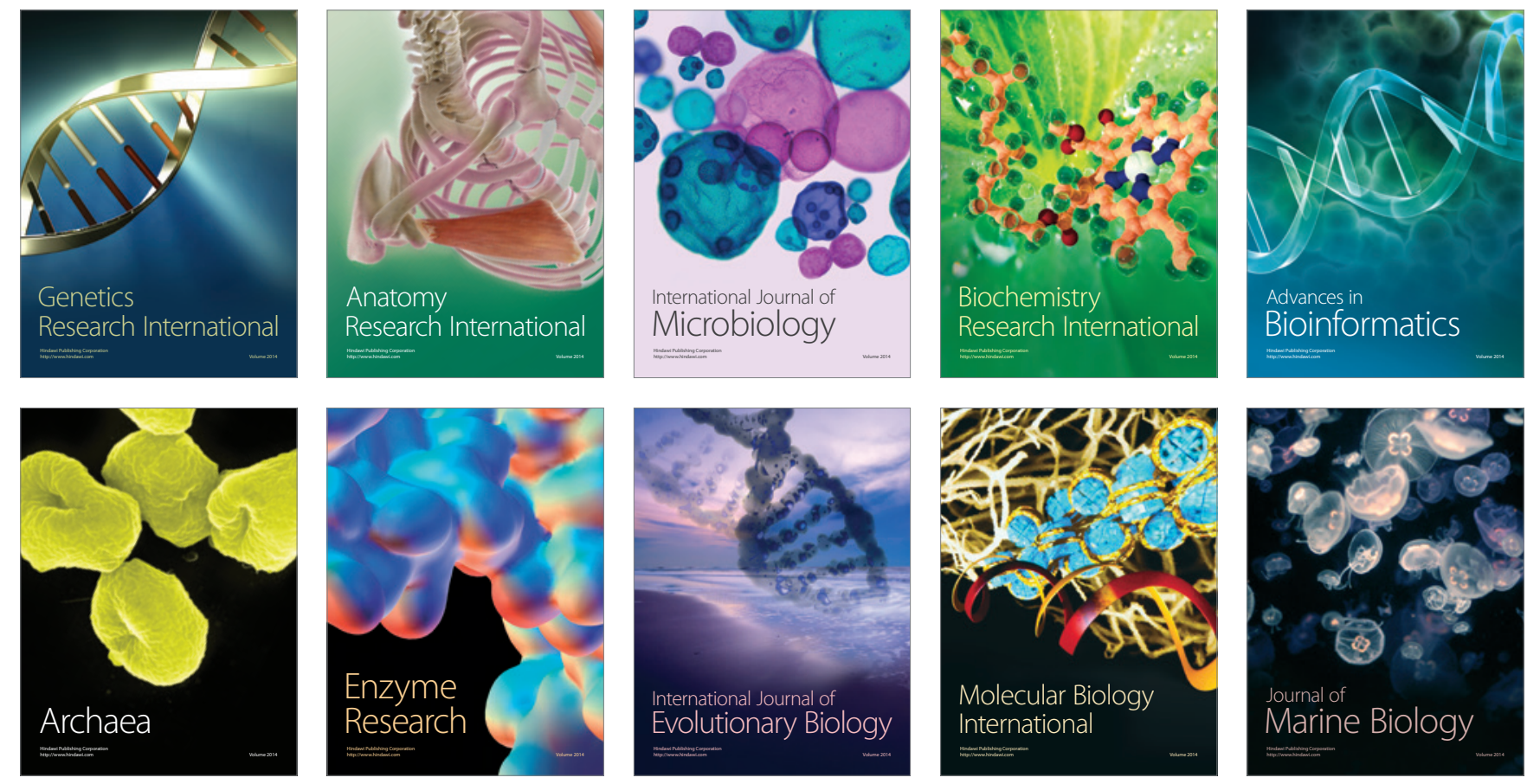